

\title{
Determination of equivalent continuum mechanical model for fractured EDZ around underground galleries by homogenization
}

\author{
Ahmad Pouya, Zaky Bendjeddou, Adrien Poutrel
}

\section{To cite this version:}

Ahmad Pouya, Zaky Bendjeddou, Adrien Poutrel. Determination of equivalent continuum mechanical model for fractured EDZ around underground galleries by homogenization. 7th Asian Rock Mechanics Symposium, ARMS2012, Oct 2012, Seoul, South Korea. pp.181-183. hal-00790555

\section{HAL Id: hal-00790555 \\ https://hal.science/hal-00790555}

Submitted on 20 Feb 2013

HAL is a multi-disciplinary open access archive for the deposit and dissemination of scientific research documents, whether they are published or not. The documents may come from teaching and research institutions in France or abroad, or from public or private research centers.
L'archive ouverte pluridisciplinaire HAL, est destinée au dépôt et à la diffusion de documents scientifiques de niveau recherche, publiés ou non, émanant des établissements d'enseignement et de recherche français ou étrangers, des laboratoires publics ou privés. 


\title{
Determination of equivalent continuum mechanical model for fractured EDZ around underground galleries by homogenization
}

\author{
$\underline{\text { A. Pouya }}^{\mathrm{a}^{*}}$, Z. Bendjeddou ${ }^{\mathrm{b}}$, A. Poutrel ${ }^{\mathrm{c}}$ \\ ${ }^{a}$ Senior Researcher, Laboratoire Navier (ENPC/IFSTTAR/CNRS), Champs/Marne, France \\ ${ }^{b}$ Researcher, Laboratoire Navier (ENPC/IFSTTAR/CNRS), Champs/Marne, France \\ ${ }^{c}$ Researche-Engineer, ANDRA, Châtenay-Malabry, France \\ *Corresponding Author’s E-mail: ahmad.pouya@enpc.fr
}

Keywords: EDZ, fracture, homogeneization, continuum equivalent model, claystone

\begin{abstract}
An Equivalent Continuum Model (ECM) is proposed in order to represent the hydromechanical behaviour of the fractured Excavation Damaged Zone (EDZ) around deep underground galleries excavated in claystone. The fractures observed in these galleries show a regular trend that makes possible elaboration of ECM based on theoretical homogenization methods. The ECM established first for plane fracture surfaces is then extended to curved, conical shape, fractures surfaces based on some simplification assumptions. The stress and displacement fields have been compared around the EDZ by using the ECM in numerical simulation or by introducing the fractures individually as discontinuities in the model. The results show that however the size of EDZ is too small compared to that of Representative Elementary Volume (REV) considered in homogenization approaches, the ECM obtained in this way seems reproducing well the fractured EDZ behaviour.
\end{abstract}

\section{Introduction}

The Excavation Damaged Zone (EDZ) around deep underground galleries excavated in claystone for the Underground Repository Laboratory (URL) includes several zones showing different types of cracking and/or fracturing. In the vicinity of the wall of the URL galleries, a fractured zone is observed that spreads out on a distance from $1 \mathrm{~m}$ to $3 \mathrm{~m}$ from the wall (ANDRA 2008). At a larger distance from the wall another zone with micro-cracks is observed. The first zone includes different families of fractures with different geometries and origins. The zone called EDZ by ANDRA contains a dense and highly connected fractures network. In this paper, the zone called fractured EDZ contains mainly a family of shear fractures called "chevron", that have approximately the shape of conical surfaces slightly flattened with respect to the horizontal plane (Figure 1). 


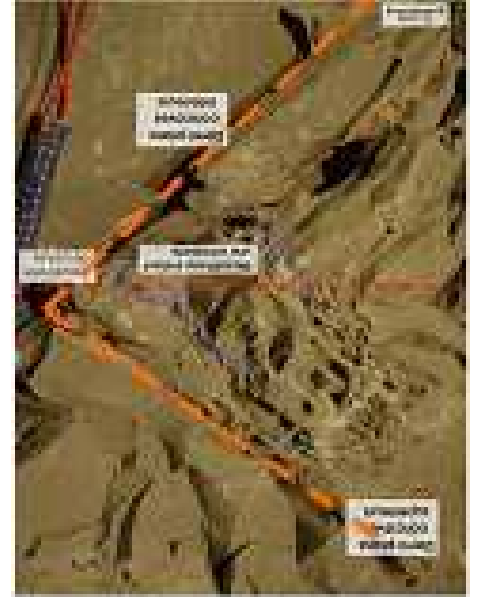

(a)

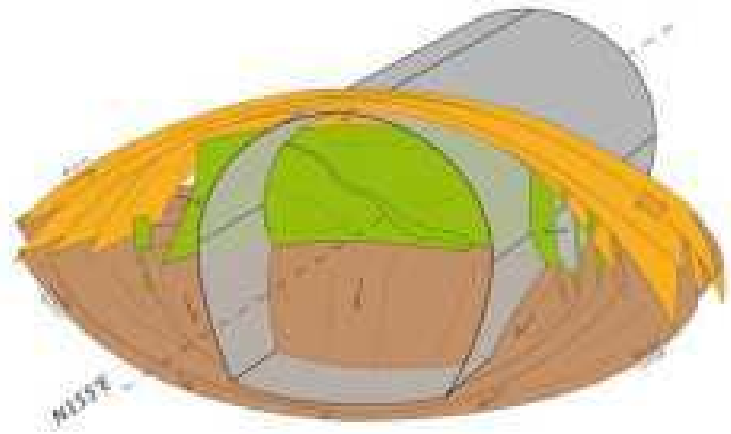

(b)

Figure 1. Fractured EDZ around deep galleries in claystone (a): fractures outcropping on the wall (photo), (b): geometrical model of fractures (GEOTER 2011)

The chevrons observed in the galleries at a depth of $490 \mathrm{~m}$ are regularly spaced from $50 \mathrm{~cm}$ to $1 \mathrm{~m}$ apart along the axis of the gallery, making an angle of about $45^{\circ}$ with this axis (GEOTER 2011) (Figure 2a). These fractures have a significant effect on the hydromechanical properties of the EDZ. Due to the large number of fractures, introducing them individually in the modelling leads to heavy and not easy to handle numerical models and to too long calculations. In this context, it is fruitful to determine a Equivalent Continuum Material (ECM) for the EDZ, which includes the effects of the fractures. The authors do not want to predict or explain here the origin and development process of the existing fractures. Based on the exisence of these fractures, this paper focuses on the elaboration of ECM for the fractured EDZ. This model takes into account the fracture effects under the assumption of their constant geometry, in order to enable predicting the behaviour of the EDZ and its evolution for futures loads applied on the gallery.

In the following section, an ECM for the chevron fractures of the EDZ is proposed. First, the constitutive equations for the the two constituents of the heterogeneous medium, i.e. the intact rock and the fractures or joints are defined. Then, the ECM is built using homogeneization techniques, based on the approximation of chevron fractures by their tangent planes. By allowing the normal vector $\underline{n}$ to the fracture plane and the spacing $D$ of fractures to vary from one point to another, the model can be extended to more complex fracture geometries. Lastly, the validation of the ECM is done by comparing the results obtained by discontinuous and continuous computations. The discontinuous modelling corresponds to introducing the discrete fractures in the numerical model.

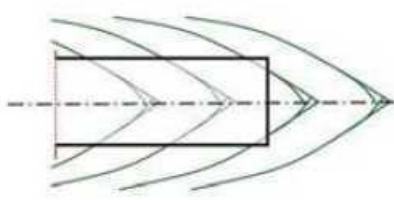

(a)

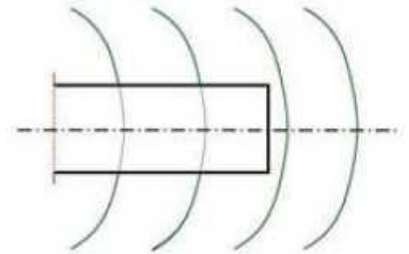

(b)

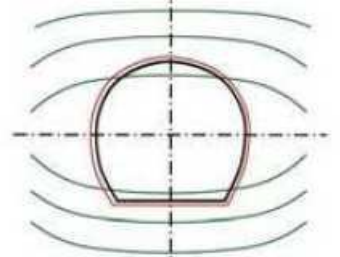

(c)

Figure 2. Schematic representation chevron fractures in (a) a vertical plane (b) a horizontal plane (c) a vertical plane perpendicular to the axis (ANDRA, 2008). 


\section{Continuum Equivalent Model}

\subsection{The Representative Elementary Volume}

The EDZ is not very large compared to the fractures size, so the condition of a macroscopic scale infinitely larger than the microscopic scale (scale of heterogeneities that here are the fractures) required for homogenisation or upscaling approaches is not satisfied in this case. The REV is considered as a portion of the EDZ representing the fractures geometry that has approximately the same size that the fractures. So, it may be not fully justified to apply a homogenization approach. However, this approach will be used in this paper to define the ECM and the result will be tested by the numerical simulation.

For this purpose, the geometry of the fractures is first simplified and assumed to correspond to conical surfaces with axial symmetry around the axis of the gallery (Figure 3).

The local behaviour of the ECM is deduced from the model of an infinite medium containing a family of planar, parallel and equidistant fractures (Figure 4) perpendicular to a unit vector $\underline{n}$. This behaviour has thus the axial symmetry around the axis $\underline{n}$.

First, we determine the behaviour on one point of the EDZ with the assumption that there is locally a family of infinite plane and equidistant fractures. To account for the actual geometry of the fractures, the parameters of the model, i.e. the orientation and the spacing between fractures, will be given, in the next steps of modelling, values depending on the point considered in the EDZ.

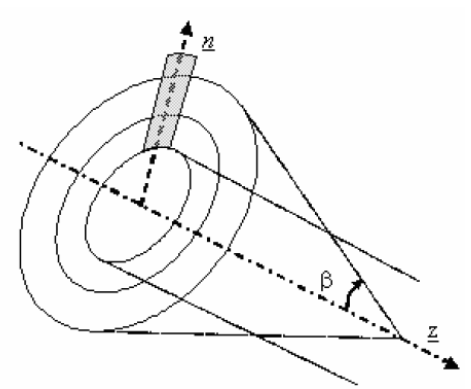

(a)

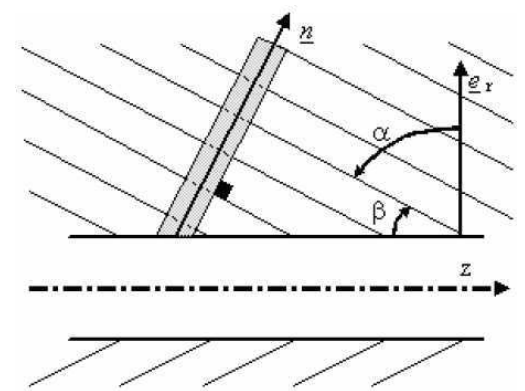

(b)

Figure 3: Geometry of the conical fractures in the global coordinate system, (a) along $e_{\mathrm{z}}$ and (b) in a $3 \mathrm{D}$ view.

\subsection{Elastic behaviour}

This section focuses on the development of the elastic behaviour of the ECM. The geometry of the model presents axial symmetry around the normal vector to the fractures planes. The elastic homogenized behaviour of the EDZ, has the transverse isotropy around the axis $\underline{n}$ and depends on five intrinsic parameters. By taking $\underline{n}$ for the third axis of coordinates, the five independent parameters are the components $s_{11}, s_{33}, s_{12}, s_{13}, s_{44}$ of the compliance matrix shown at equation (1). 


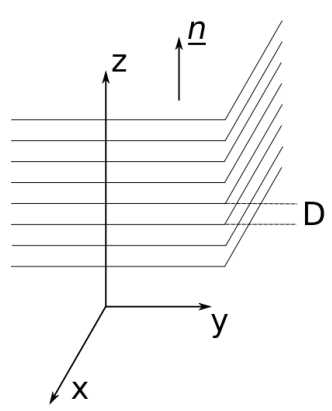

Figure 4. Geometrical model for a material with infinite planes and equidistant fractures

$$
\left[\begin{array}{c}
\varepsilon_{11} \\
\varepsilon_{22} \\
\varepsilon_{33} \\
2 \varepsilon_{23} \\
2 \varepsilon_{13} \\
2 \varepsilon_{12}
\end{array}\right]=\left[\begin{array}{llllll}
s_{11} & s_{12} & s_{13} & & & \\
& s_{11} & s_{13} & & & \\
& & s_{33} & & & \\
& & & s_{44} & & \\
& & & & s_{44} & \\
& & & & & s_{66}^{*}
\end{array}\right]\left[\begin{array}{c}
\sigma_{11} \\
\sigma_{22} \\
\sigma_{33} \\
\sigma_{23} \\
\sigma_{13} \\
\sigma_{12}
\end{array}\right]
$$

These parameters are related to the Young's modulus $E$ of the rock matrix, its Poisson's ratio $v$ and its shear modulus $G=E /[2(1+v)]$, the normal and tangent elastic stiffness of the fractures $k_{n}$ and $k_{t}$, and the fractures spacing $D$, by the following relations:

$$
s_{11}=\frac{1}{E}, \quad s_{12}=s_{13}=\frac{-v}{E}, \quad s_{33}=\frac{1}{E}+\frac{1}{k_{n} D}, \quad s_{44}=\frac{1}{G}+\frac{1}{k_{n} D}, \quad s_{66}^{*}=2\left(s_{11}-s_{12}\right)
$$

All the coefficients of the elastic part of the ECM are now determined in the local system of the coordinates related to the fractures plane. The next step consists in writing the elastic tensor function of the coordinates of the local unit normal $\underline{n}$ in the global system of coordinates related to the galery's axis. For this purpose, the components of the stifness tensor, $c_{\alpha \beta}$, are deduced from inversion of the compliance tensor to find:

$$
\begin{aligned}
& c_{11}=\left(1+M_{n}-v^{2}\right) E / M, \quad c_{12}=v\left(1+M_{n}+v\right) E / M, \quad c_{13}=v(1+v) E / M \\
& c_{33}=\left(1-v^{2}\right) E / M, \quad c_{44}=E /\left[2(1+v)+M_{t}\right]
\end{aligned}
$$

with:

$$
M=(1+v)\left[\left(1+M_{n}\right)\left((1-v)-2 v^{2}\right], \quad M_{n}=\frac{E}{K_{n} D}, \quad M_{t}=\frac{E}{K_{t} D}\right.
$$

Then the stiffness tensor in the global coordinate system is expressed as:

$$
\begin{aligned}
C_{i j k l}= & b_{1} \delta_{i j} \delta_{k l}+b_{2}\left(\delta_{i k} \delta_{j l}+\delta_{i l} \delta_{j k}\right)+b_{3}\left(\delta_{i j} n_{k} n_{l}+\delta_{k l} n_{i} n_{j}\right) \\
& +b_{4}\left(\delta_{i k} n_{j} n_{l}+\delta_{i l} n_{j} n_{k}+\delta_{j k} n_{i} n_{l}+\delta_{j l} n_{i} n_{k}\right)+b_{5} n_{i} n_{j} n_{k} n_{l}
\end{aligned}
$$

with the coeficients $b_{1}$ to $b_{5}$ defined by: 


$$
b_{1}=c_{12}, \quad b_{2}=\left(c_{11}-c_{12}\right) / 2, \quad b_{3}=c_{13}-c_{12}, \quad b_{4}=c_{44}-\left(c_{11}-c_{12}\right) / 2, \quad b_{5}=c_{33}+c_{11}-2 c_{13}-4 c_{44}
$$

The vector $\underline{n}$ introduced in (5) is the unit normal to the fractures plane that varies around the EDZ and is calculated at every point of the EDZ. According to its representation at Figure 3 for conical fractures, its compoments in the global cylindric coordinate system can bewritten as follows:

$$
n_{1}=\cos \alpha \cos \theta, \quad n_{2}=\cos \alpha \sin \theta, \quad n_{3}=\sin \alpha
$$

If the chevron fractures of the gallery are approximated by conical fractures around the axis of the gallery, the parameters $b_{1}$ to $b_{5}$ are constant everywhere, and $\underline{n}$ is given by (7) with constant angle $\alpha$. This technique allows to consider fractures shapes more complex than the conical ones, for instance for curved surfaces, by supposing that $\underline{n}$ and $D$ are depending on the position around the gallery, and so function of $r$ and $\theta$.

\subsection{Plastic behaviour}

The irreversible and instantaneous strains of the homogeneized EDZ can be modeled using an elastoplastic law. The mechanisms of the EDZ plastic strains are the key to determine the plastic criterion and potential accurately for the homogenized EDZ behaviour. The plastic strains can come either from the rock matrix or from the fractures. For the rock, a non associated Drucker-Prager law (Drucker and Prager, 1952), was chosen, as it has been applied successfully to the study of the elastoplastic strains of the Callovo-Oxfordian claystone (Conil et al., 2004a,b; Hoxha et al., 2007; Abou-Chakra Guéry et al., 2008). The yield function $F^{\mathrm{R}}$ and the plastic potential $G^{R}$ for the rock matrix have the same form:

$$
F^{R}(\boldsymbol{\sigma})=q+\gamma \sigma_{m}-C_{0}, G^{R}(\boldsymbol{\sigma})=q+\beta \sigma_{m}
$$

where $\gamma$ and $C_{0}$ are two materials parameters, $\sigma_{\mathrm{m}}=\left(\sigma_{i i}\right) / 3$ and $q=\left(3 J_{2}\right)^{1 / 2}$ where $J_{2}$ is the second invariant of the stress tensor: $J_{2}=s_{i j} s_{i j} / 2$ with $s_{i j}$ the stress deviator tensor: $s_{i j}=\sigma_{i j}\left(\sigma_{m}\right) \delta_{i j}$.

The plastic behaviour of fractures is described by a non associated Mohr-Coulomb criterion:

$$
F^{F}(\underline{\sigma})=\|\underline{\tau}\|+\sigma_{n} \tan \phi-C, \quad G^{F}(\underline{\sigma})=\|\underline{\tau}\|+\sigma_{n} \tan \psi
$$

with:

$$
\underline{\sigma}=\sigma . \underline{n}, \quad \sigma_{n}=\underline{n} . \boldsymbol{\sigma} \cdot \underline{n}, \quad\|\underline{\tau}\|=\sqrt{\underline{n} \cdot \sigma \cdot \sigma \cdot \underline{n}-(\underline{n} \cdot \sigma \cdot \underline{n})^{2}}
$$

The elastic domain of the homogenized EDZ material is the intersection of the elastic domains of fractures and rock matrix, defined hence by:

$$
F^{H}(\boldsymbol{\sigma})<0
$$

where the homogenized criterion $F^{H}(\boldsymbol{\sigma})$ is given by:

$$
F^{H}(\boldsymbol{\sigma})=\operatorname{Max}\left\{F^{R}(\boldsymbol{\sigma}), F^{F}(\boldsymbol{\sigma})\right\}
$$

The plastic strain rule of the homogenized EDZ is defined as a multi-mechanisme plastic yield rule (Halphen \& Nguyen, 1975; Pouya,1993, 2004) by the following equations: 


$$
\dot{\boldsymbol{\varepsilon}}_{p}^{H}=\sum_{\mathrm{i}=\mathrm{R}, \mathrm{F}} \lambda^{\mathrm{i}} \frac{\partial G^{\mathrm{i}}}{\partial \boldsymbol{\sigma}} \quad \text { with } \lambda^{i} \geq 0 \text { and } \lambda^{i}=0 \quad \text { if } F^{i}<0 \text { or if } F^{i}=0 \text { and } \frac{\partial F^{\mathrm{i}}}{\partial \boldsymbol{\sigma}}: \dot{\boldsymbol{\sigma}}<0
$$

The mechanical parameters chosen for the intact rock and fractures are given in the Table 1.

\section{Numerical simulation}

The ECM derived in the previous section is implemented in the Finite Elements codes CESARLCPC and applied to the modelling of underground galleries dug in the Meuse Haute-Marne URL. According to data provided by ANDRA (ANDRA, 2005), the EDZ can extend to a distance of 3m from the wall. The numerical simulations are made on a $3 \mathrm{~m}$ radius gallery (Figure 5), with a depth of excavation of $20 \mathrm{~m}$. The axis of the gallery, vertical in the figure, is horizontal for the real gallery. The studied system has a width of $18 \mathrm{~m}$ and a height $35 \mathrm{~m}$. The axial symmetry of the geometry is a strong hypothesis, since the data provided by ANDRA (ANDRA, 2008) show that the extents of the chevron fractures are not perfectly regular. However, this hypothesis simplifies significantly the computations and allows the validity demonstration of the ECM proposed here above. To this purpose, several sets of computations are run. Complexities like the curved aspect of fracture surfaces and the plastic behaviour are introduced gradually in calculation. In the first set of simulations, chevron fractures are approximated by conical surfaces and elastic behaviour. In the second one, the curvature of the chevrons is modelled using an approximate hyperbolic shape according to observation data. The plasticity is then introduced in these calculations. For each set, two types of modelling, one by ECM and the other by introducing individually the fractures in the model as joint elements (Pouya et al., 2009) are computed.

The in stresses have been estimated by (ANDRA, 2005). To reproduce the in situ conditions of the URL, compression stresses of 12.7 MPa and 12.4 MPa (or 16.5 MPa according to the orientation of the gallery) are applied on the right edge and at the bottom of the model respectively. Displacements along the minor stress $\sigma_{h}$ are blocked on the top of the model, and displacements along the major stress $\sigma_{H}$ are blocked on its left edge. The wall of the gallery is stress-free. Values of the mechanical parameters are given in Table 1.

The mesh used for chevron fractures computations as well as the boundary conditions are presented at Figure 5. In this figure the fractures of the EDZ can be seen (red lines) as introduced in the model.

Table 1. Mechanical parameters of the intact rock and of fractures

\begin{tabular}{|l|l|l|l|l|}
\hline Intact Rock & $E(\mathrm{GPa})$ & $v$ & $C(\mathrm{MPa})$ & $\phi=\psi\left({ }^{\circ}\right)$ \\
\hline & 4.0 & 0.3 & 4.5 & 25 \\
\hline Fractures & $\alpha\left(^{\circ}\right)$ & $\mathrm{D}(\mathrm{m})$ & $\mathrm{K}_{\mathrm{n}}(\mathrm{MPa} / \mathrm{m})$ & $\mathrm{K}_{\mathrm{t}}(\mathrm{MPa} / \mathrm{m})$ \\
\hline & 45 & 0.42 & 3000 & 1000 \\
\hline
\end{tabular}




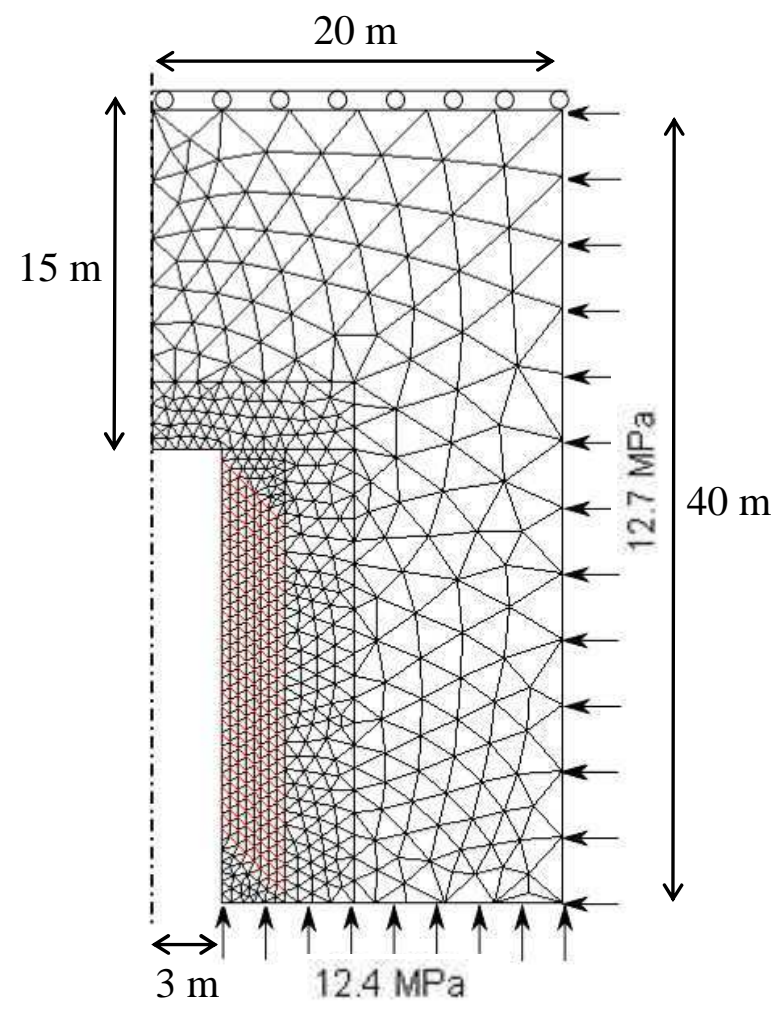

Figure 5. Mesh used for the conical fractures computations

\section{Results and Discussion}

The results of the stress and displacement fields obtained in the simulations described in previous sections allow the comparison between the ECM and the discontinuous models. Here we focus on the comparison of displacement fields. The radial displacements on the wall of the gallery are presented in Figure 6. The Figure 6a displays the results for the elastic fractures with curved surfaces. The curve in red presents the displacement at the wall of the gallery obtained with the discontinuous model (fractures modelled individually). The displacements obtained by using the ECM are displayed in green. A good agreement between the two curves is observed. The difference between the two curves at the bottom of the figure is due to some border effects at the bottom of the domain. Figure $6 \mathrm{~b}$ displays the same results for elastoplastic behaviour of the intact rock and fractures.

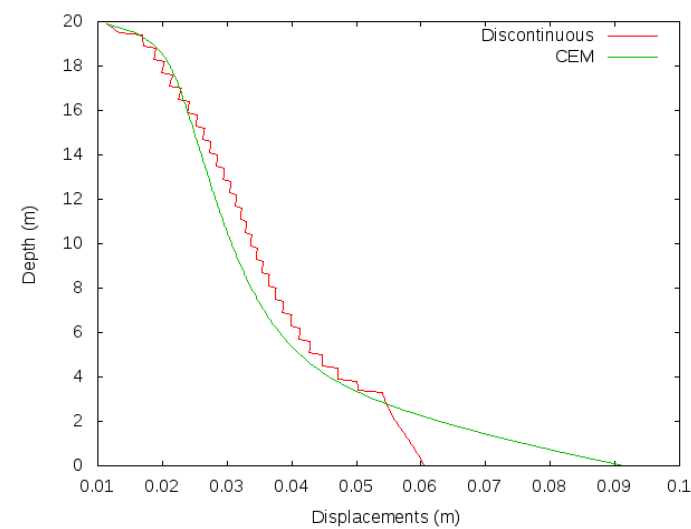

(a)

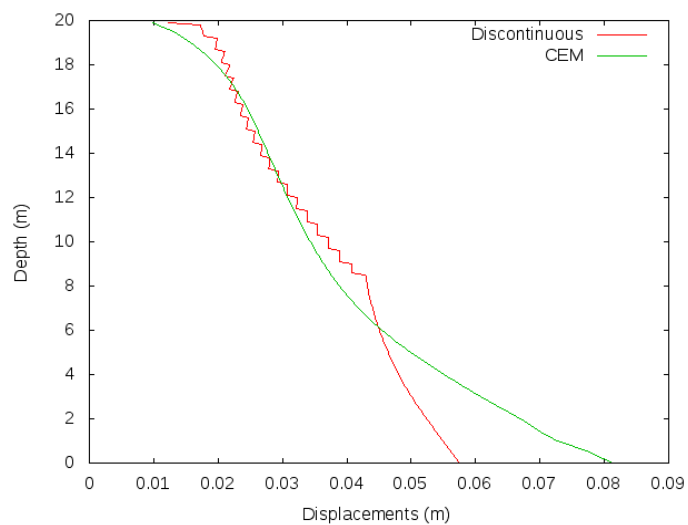

(b)

Figure 6. Comparison between the ECM and the discontinuous modelling for the (a) elastic and (b) elasto-plastic behaviours of chevron fractures 
The figure 7 displays the contours of radial stress around the gallery obtained in another simulation process (a little different geometry) first by discontinuous modelling and then by ECM for the case of curved surface fracture with elastoplastic behaviour. Due to the increased complexity of the model (plasticity), the ECM model becomes more approximate and there is a little more difference between the results of the two types of modelling. However the concordance can be considered sufficient for engineering purposes given that the ECM brings a great simplification in numerical modelling.

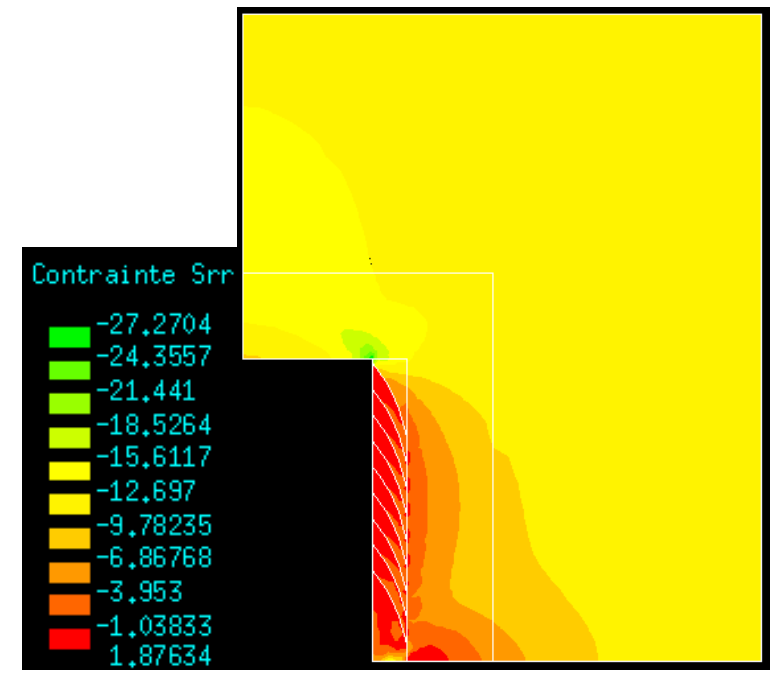

(a)



(b)

Figure 7. Contours of the radial stress $\left(\sigma_{\mathrm{rr}}, \mathrm{MPa}\right)$ around the gallery obtained by discontinuous modelling of elasto-plastic curved chevron fractures (a) and by ECM (b)

Finally, the figure 8 represents the contour of the plastic deformation zone around the gallery obtained by different ECM established for different zones around the gallery. The strong anisotropy of the ECM that is related to the direction of discrete fractures give special trends to the plastic zone contour in this figure.

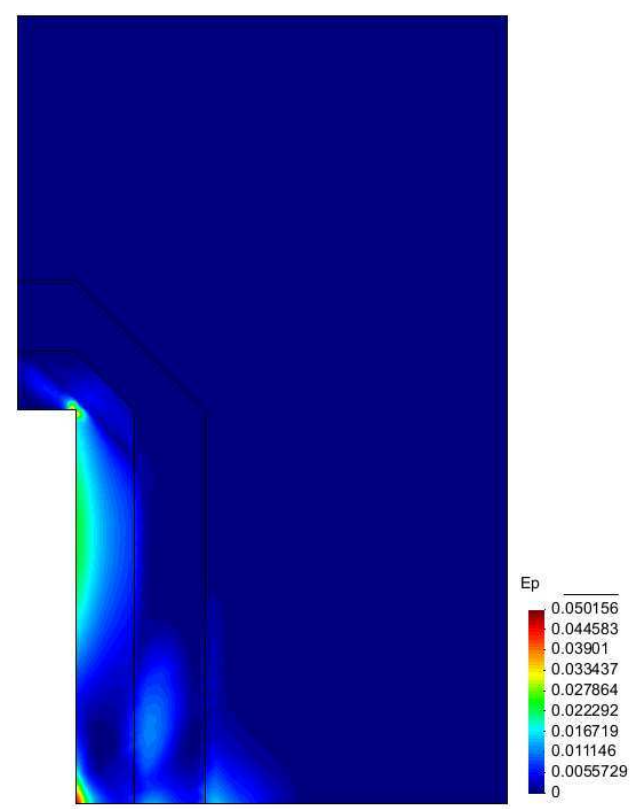

Figure 8. Contours of the plastic strain around the gallery obtained by using in different ECM in different zones around the gallery with different distributions of cracks and fractures. 


\section{Conclusions}

An equivalent continuum model (ECM) for the chevron fractures in the EDZ around the galleries of the underground repository laboratory in claystone is proposed. After deriving the general expression of this ECM, it is implemented in a Finite Elements code with specific parameters of a fractured claystone. The ECM approach is validated by comparing the results of numerical simulations carried out with this model and those corresponding to direct or the discontinuous approach in which the fractures are modelled individually by joint elements. The good agreement between the two models shows the capabilities of the ECM to reproduce the discontinuous behaviour of the EDZ using a continuum approach. This approach has been extended to the hydraulic and coupled hydromechanical behaviour of the EDZ and satisfying results have been obtained.

The main conclusion from these results is that, however the REV size is not attained for the EDZ around underground galleries containing chevron fractures, the upscaling method allows to obtain an ECM which represents well the hydro-mechanical behaviour of this zone.

The use of a simplified ECM model for the elastoplastic behaviour of the EDZ allows introducing, in a next stage, more complex phenomena like viscosity and creep or effects of bolting for the study of the galleries behaviour that can not be easily introduced in a discontinuous model of EDZ including fractures.

\section{Acknowledgement}

The authors thank ANDRA, the French Nuclear Agency for Nuclear Wastes Management, for its financial support for this study.

\section{References}

Abou-Chakra Guéry, A., Cormery, F., Shao, J.F., Kondo, D. (2008) A micromechanical model of elastoplastic and damage behavior of a cohesive geomaterial. International Journal of Solids and Structures 45, 1406-1429.

ANDRA(2005) Analyse des perméabilités mesurées autour des ouvrages du LSMHM au niveau $490 \mathrm{~m}$ pour déterminer des lois empiriques utilisables dans des calculs hydromécaniques couplées en milieu continu.

ANDRA (2008) Expertise sur la fracturation induite par le creusement des galeries au niveau $-490 \mathrm{~m}$. ANDRA Report D.RP.0ILB.08.0005.A.

Conil, N., Djeran-Maigre, I., Cabrillac, R., Kun, S. (2004) Thermodynamics modelling of plasticity and damage of argillite. C. R. Mecanique 332, 841-259 848.

Conil, N., Djeran-Maigre, I., Cabrillac, R., Kun, S. (2004) Poroplastic damage model for claystones. Applied Clay Science 26, 473-487.

Drucker, D.-C., Prager, W. (1952) Soil mechanics and plastic analysis or limit design. Quart. Appl. Math. 10, 157-175.

GEOTER, "Suivi géologique du creusement et des forages en galleries GET (2009-2011), Rapport de find d'opération, ANDRA Report D.RP.0GTR.11.0022, (2011)

Halphen, B., Nguyen, Q.S. (1975) Sur les matériaux standards généralisées. J. Méc. 14, 39-63.

Hoxha, D., Giraud, A., Hommand, F., Auvray, C. (2007) Saturated and unsaturated behaviour modelling of MeuseHaute-Marne argillite. International Journal of Plasticity 23, 733-766.

Pouya A., "Deformation of multipotential elastoplastic solids : inequalities verified by stress and strain rate discontinuities", Comptes-Rendus de l'Académie des Sciences de Paris, t. 316, Série II, p. 1511-1516, 1993.

Pouya, A. (2004) A constitutive inequality in plasticity involving left-hand and right-hand rates. International Journal of Plasticity 20,1251-1279.

Pouya, A., Elmi, F., Bourgeois, E., Bémani, P. (2009) Joint elements in the Finite element code CESAR-LCPC, Application to fractured media and to interface problems. Revue Française de Géotechnique 128, 15-25 